\title{
Effect of postannealing process on $\mathrm{Bi}_{2} \mathrm{Sr}_{2.1} \mathrm{Ca}_{0.9} \mathrm{Cu}_{2} \mathrm{O}_{8+\delta}$ textured
}

\section{superconductors}

\author{
A. Sotelo ${ }^{1}$, M. A. Madre ${ }^{1}$, Sh. Rasekh ${ }^{1}$, G. Constantinescu ${ }^{1}$, M. A. Torres ${ }^{2}$, J. C. Diez ${ }^{1}$ \\ ${ }^{1}$ ICMA (CSIC-Universidad de Zaragoza). María de Luna, 3. 50018-Zaragoza. Spain. \\ ${ }^{2}$ Universidad de Zaragoza, Dpto. de Ingeniería de Diseño y Fabricación. María de Luna \\ 3, 50018-Zaragoza. Spain.
}

\begin{abstract}
Bi-2212 samples prepared by the classical solid-state method have been grown from the melt using the Laser Floating Zone (LFZ) method. They have shown good grain alignment and transport critical current densities $\left(\mathrm{J}_{\mathrm{c}}\right)$. After postannealing processes designed to produce the $\mathrm{Bi}-2212$ phase controlled decomposition, $\mathrm{J}_{\mathrm{c}}$ values have been increased in an important manner. Maximum values have been achieved when samples were thermally treated at $680{ }^{\circ} \mathrm{C}$ for $168 \mathrm{~h}$ with improvements around $80 \%$, compared with the original textured samples. The results clearly indicate that postannealing processes, when adequately controlled, produce the formation of effective pinning centers which are responsible for the raise in the measured $\mathrm{J}_{\mathrm{c}}$ values.
\end{abstract}

Keywords: Bi-2212, Directional growth, Resistivity, Critical current, Pinning. * Corresponding author: A. Sotelo, asotelo@unizar.es; Tel: +34 976762617; Fax: +34 976761957 


\section{INTRODUCTION}

The fabrication of bulk high-temperature superconductors with high electrical transport properties at $77 \mathrm{~K}$ is of great interest for their practical applications [1]. In particular, many strategies have been used in order to maximize the transport properties of BSCCO materials. Some of them are related with the preparation of high homogeneous precursors with small particle sizes using different synthetic methods [2-5]. Moreover, the effect of cationic substitution, as for example $\mathrm{Pb}^{2+}$ by $\mathrm{Bi}^{3+}[6,7]$, or metallic additions, typically metallic Ag [8,9], have been tested. Finally, other studies have been centred on the superconducting grain alignment which leads to an important raise on the electrical transport properties due to the reduction of the number of low-angle junctions [10]. The main techniques used to obtain very well aligned grains in the conducting direction can be through solid state processes, as the sinter-forging methods [11] or by directional solidification from the melt $[12,13]$. Among these last techniques, the laser floating zone has demonstrated its reliability to produce well textured materials with high electrical properties in doped and undoped $\mathrm{Bi}_{2} \mathrm{Sr}_{2} \mathrm{CaCu}_{2} \mathrm{O}_{8+\delta}(\mathrm{Bi}-2212)$ superconducting ceramics at relatively high growth rates $[14,15]$. Nevertheless, due to the incongruent melting of this phase, after the growth process, it is necessary to perform an annealing in order to recombine the secondary phases to obtain the Bi-2212 one [16].

On the other hand, it is well known that pinning centers in Bi-2212 superconducting materials play an important role on the electrical properties of this kind of superconductors. In fact, many works are dealing with the formation of pinning centers by addition of different compounds, as $\mathrm{MgO}$ [17], transition metal oxides-based materials [18], rare earth oxides [19], etc, or by the introduction of intrinsic structural 
defects promoted, for example, by neutron irradiation [20] or by controlled decomposition of the superconducting phase [21].

The aim of this work is developing a simple process to produce effective pinning centers, which increase the $\mathrm{J}_{\mathrm{c}}$ values in LFZ grown $\mathrm{Bi}-2212$ superconducting ceramics, by the controlled decomposition of the superconducting phase.

\section{EXPERIMENTAL}

Samples composition has been chosen from the phase diagram equilibrium for the pseudo-binary $\mathrm{Bi}_{2.18} \mathrm{Sr}_{3-\mathrm{y}} \mathrm{Ca}_{\mathrm{y}} \mathrm{Cu}_{2} \mathrm{O}_{8+\delta}$ system [22], taking $\mathrm{y}=0.9$. This value has been selected in order to get the samples out of the Bi-2212 stability region with relatively small changes in temperature. The initial $\mathrm{Bi}_{2} \mathrm{Sr}_{2.1} \mathrm{Ca}_{0.9} \mathrm{Cu}_{2} \mathrm{O}_{8+\delta}$ materials used in this work were prepared by the classical solid state method from commercial $\mathrm{Bi}_{2} \mathrm{O}_{3}(98 \%$, Panreac), $\mathrm{SrCO}_{3}\left(98+\%\right.$, Panreac), $\mathrm{CaCO}_{3}$ (98.5\%, Panreac), and $\mathrm{CuO}(98 \%$, Panreac) powders. They were weighed in the appropriate proportions and ball-milled in acetone media for 30 minutes at $300 \mathrm{rpm}$ in order to get an homogeneous suspension which has been subsequently dried in an IR quick dryer system. The dry mixture was then manually milled to obtain a homogeneous mixture. This powder has then been thermally treated twice at 750 and $800{ }^{\circ} \mathrm{C}$ for about 12 hours for each treatment, under air, with an intermediate manual milling, in order to assure the complete decomposition of the carbonates. Otherwise, the presence of carbonates would form $\mathrm{CO}_{2}$ bubbles in the molten zone produced in the LFZ process which can produce the solidification front destabilization. The resulting powders were then cold isostatically pressed at $\sim 200 \mathrm{MPa}$ to obtain green ceramic cylinders which were subsequently used as feed in a LFZ device [23] equipped with a continuous power Nd:YAG laser $(\lambda=1.06 \mu \mathrm{m})$. The processing of the different samples has been performed in the same conditions; they were 
directionally solidified downwards from the melt at $30 \mathrm{~mm} / \mathrm{h}$ with a seed rotation of 3 rpm. Moreover, in order to assure compositional homogeneity of the molten zone, an opposite feed rotation of $15 \mathrm{rpm}$ has also been performed. Finally, after the texturing process, long (more than $15 \mathrm{~cm})$ and geometrically homogeneous $(\sim 2 \mathrm{~mm}$ diameter) textured cylindrical rods have been produced.

Bi-2212 ceramics present incongruent melting and, in consequence, after the directional solidification process, it is necessary to perform a thermal treatment in order to form the Bi-2212 superconducting phase [24, 25]. This annealing process was performed under air, and consisted in two steps: $60 \mathrm{~h}$ at $860{ }^{\circ} \mathrm{C}$ to produce the Bi-2212 phase, followed by $12 \mathrm{~h}$ at $800{ }^{\circ} \mathrm{C}$ to adjust the oxygen content in the superconducting phase and, finally, quenched in air to room temperature. Before the thermal treatment, as-grown samples were cut into pieces of the adequate dimensions for the electrical measurements $(\sim 3 \mathrm{~cm}$ long). Moreover, four silver contacts were painted on these samples, two of about $5 \mathrm{~mm}$ at both ends of the bars for the current contacts and two small ones, spaced out about 10 $\mathrm{mm}$ in the center of the bar, for the voltage measurements. After annealing, the silver contacts have typical resistance values below $1 \mu \Omega$.

After annealing process, some of the samples were kept in order to be characterised while other ones underwent to postannealing treatments. The adequate processing temperatures $\left(680\right.$ and $\left.900{ }^{\circ} \mathrm{C}\right)$ were selected from the phase diagram equilibrium [22] in order to get a controlled decomposition of the superconducting phase. Samples were then thermally treated at 680 and $900{ }^{\circ} \mathrm{C}$ for times ranging between $24-312 \mathrm{~h}$ and 1-4 min, respectively.

Phase determination, before and after postannealing processes, has been performed on annealed samples using X-ray powder diffraction measurements (Rigaku D/max-B) with $2 \theta$ ranging between 10 and $60^{\circ}$. Microstructural characterization was made on 
polished longitudinal cross-sections of the samples in a scanning electron microscope (SEM, JEOL JSM 6400) equipped with an energy dispersive spectroscopy (EDX) system.

Electrical measurements were performed by the conventional four-point probe configuration. Resistivity as a function of temperature, from 77 to $300 \mathrm{~K}$, was measured using a dc current of $1 \mathrm{~mA}$, in order to determine the critical temperature $\left(\mathrm{T}_{\mathrm{c}}\right)$. Critical current density $\left(\mathrm{J}_{\mathrm{c}}\right)$ values were determined at $77 \mathrm{~K}$, from the I-V curves, using the 1 $\mu \mathrm{V} / \mathrm{cm}$ standard criterion.

\section{RESULTS AND DISCUSSION}

As reported previously [15], after annealing processes performed on the as-grown materials, nearly pure Bi-2212 phase is obtained. Some of the annealed samples were thermally treated at different temperatures, under $\left(680^{\circ} \mathrm{C}\right)$ or over $\left(900^{\circ} \mathrm{C}\right)$ the stability temperatures range for the $\mathrm{Bi}_{2} \mathrm{Sr}_{2.1} \mathrm{Ca}_{0.9} \mathrm{Cu}_{2} \mathrm{O}_{8+\delta}$ composition. The time lengths for the different treatments have been between $24-312 \mathrm{~h}$ for samples postannealed at $680{ }^{\circ} \mathrm{C}$ and 1-4 min for those heated at $900{ }^{\circ} \mathrm{C}$. The time limit for samples treated at $900{ }^{\circ} \mathrm{C}$ has been due to the formation of a big amount of liquid phase which stuck the samples to the alumina boat.

Powder XRD patterns, performed on annealed and postannealed samples, are displayed in Fig. 1 where the peaks corresponding to the Bi-2212 phase have been indexed [26]. From this graphic, it is clear that annealed samples are composed of nearly pure Bi2212 phase (see Fig. 1a), indicating that the annealing conditions have been optimally designed to produce the superconducting phase. This is a very important point when taking into account that the quaternary $\mathrm{Bi}_{2} \mathrm{O}_{3}-\mathrm{SrO}-\mathrm{CaO}-\mathrm{CuO}$ system shows more than 20 stable phases [22]. When these annealed samples are subjected to thermal treatments 
at temperatures out of the Bi-2212 phase stability range, it should be decomposed following the equations [22]:

$\mathrm{Bi}_{2} \mathrm{Sr}_{2} \mathrm{CaCu}_{2} \mathrm{O}_{8+\delta} \rightarrow \mathrm{Bi}_{2+\mathrm{x}}(\mathrm{Sr}, \mathrm{Ca})_{2} \mathrm{CuO}_{6+\delta}+\mathrm{Sr}_{3} \mathrm{Bi}_{2} \mathrm{O}_{6}+\mathrm{Sr}_{14} \mathrm{Cu}_{24} \mathrm{O}_{41-\mathrm{x}}$ (at $680{ }^{\circ} \mathrm{C}$ )

$\mathrm{Bi}_{2} \mathrm{Sr}_{2} \mathrm{CaCu}_{2} \mathrm{O}_{8+\delta} \rightarrow(\mathrm{Sr}, \mathrm{Ca}) \mathrm{CuO}_{2}+$ liquid (at $900{ }^{\circ} \mathrm{C}$ )

The decomposition process at $680^{\circ} \mathrm{C}$ is very slow while the one at $900{ }^{\circ} \mathrm{C}$ is fast, explaining the different time lengths used for each temperature.

After the postannealing process, XRD characterization has shown no modification of the registered patterns, as it can be clearly seen in Fig. 1b-e, independently of temperature and time. This effect can be attributed to the decomposition of a slight fraction of Bi-2212 phase content leading to secondary phases with very small particle sizes and proportions.

Fig. 2 shows SEM images corresponding to longitudinal polished sections of annealed and postannealed samples. In the annealed samples (Fig. 2a), three different phases can be found (numbered for clarity). The phase marked as \#1 (grey contrast) corresponds to the $\mathrm{Bi}-2212$ as the major one, \#2 (light grey contrast) has been associated with the Bi2201 phase, and \#3 (dark grey contrast) has been identified as $(\mathrm{Sr}, \mathrm{Ca}) \mathrm{CuO}_{2}$ one. When considering the postannealed samples, phases composition changes accordingly to the phase diagram equilibrium due to the Bi-2212 decomposition. As a consequence, a slight increase on the amount of secondary phases can be observed in samples subjected to the postannealing processes, compared with the annealed ones. For samples treated at $680{ }^{\circ} \mathrm{C}$ for 168 and $312 \mathrm{~h}$ (Figs. $2 \mathrm{~b}$ and c, respectively), Bi-2212 is still the major phase, while the secondary phases composition changes, compared with the annealed samples. In these samples, the light (\#4), white (\#5), and dark grey (\#6) contrasts show the $\mathrm{Bi}_{2+\mathrm{x}}(\mathrm{Sr}, \mathrm{Ca})_{2} \mathrm{CuO}_{6+\delta}, \mathrm{Sr}_{3} \mathrm{Bi}_{2} \mathrm{O}_{6}$, and $\mathrm{Sr}_{14} \mathrm{Cu}_{24} \mathrm{O}_{41-\mathrm{x}}$ composition, respectively, which are in agreement with the phases found in the low temperature region of the phase diagram 
[22]. Of course, it is difficult to distinguish between white and light grey contrast in the micrographs but they can be easily identified taking into account that $\mathrm{Bi}_{2+\mathrm{x}}(\mathrm{Sr}, \mathrm{Ca})_{2} \mathrm{CuO}_{6+\delta}$ appears as isolated grains, $\mathrm{Sr}_{3} \mathrm{Bi}_{2} \mathrm{O}_{6}$ appears surrounding the $\mathrm{Sr}_{14} \mathrm{Cu}_{24} \mathrm{O}_{41-x}$ phase. In the case of samples postannealed at $900{ }^{\circ} \mathrm{C}$ for 2 and $4 \mathrm{~min}$ (Figs. 2d and e, respectively), only a new phase has been identified, when compared with the annealed sample. It can be observed as black contrast (\#7 in Fig. 2d) with $(\mathrm{Sr}, \mathrm{Ca}) \mathrm{Cu}_{2} \mathrm{O}_{3}$ composition while the rest of the phases are the same observed in the annealed samples.

All the data discussed previously clearly indicate that the postannealing processes produce microstructural changes which are in agreement with the previously published phase diagram equilibrium [22]. In any case, these changes are not important enough to be detected by the powder RXD technique, probably due to their low extent.

Fig. 3 shows the temperature dependence of the resistivity for some samples (for clarity) before ( $\bullet$ ) and after postannealing at different temperatures and times: $680{ }^{\circ} \mathrm{C}$ for $168 \mathrm{~h}(\Delta) ; 680^{\circ} \mathrm{C}$ for $321 \mathrm{~h}(\boldsymbol{\square}) ; 900{ }^{\circ} \mathrm{C}$ for $2 \mathrm{~min}(\diamond)$; and $900{ }^{\circ} \mathrm{C}$ for $4 \mathrm{~min}(+)$. The $T_{c}$ values for all the samples are summarized in Table I. From these data and Fig. 3, it can be easily observed that all the values are in a very small temperature range, indicating that the postannealing process slightly affects $T_{c}$ and room temperature resistivity values.

Critical current intensity and transport critical current density, at $77 \mathrm{~K}$, for annealed and postannealed samples, are displayed in Table II. From these data, it can be easily deduced that $\mathrm{J}_{\mathrm{c}}$ increases with the postannealing process, in all cases, compared with the annealed samples. Moreover, postannealed samples follow the same evolution, independently of temperature; they start to raise $\mathrm{J}_{\mathrm{c}}$ values until they reach a maximum, at $168 \mathrm{~h}$ for samples treated at $680{ }^{\circ} \mathrm{C}$ and at $2 \mathrm{~min}$ for those treated at $900{ }^{\circ} \mathrm{C}$, and start 
to slowly decrease. In order to have a clearer general view of this evolution, in Fig. 4 it is presented the $J_{c}$ increase (\%) as a function of the postannealing time at 680 (Fig. 4a) and $900{ }^{\circ} \mathrm{C}$ (Fig. 4b). These data evidence that the additional thermal treatments, performed after the annealing process, lead to an important raise on the transport electrical properties of these textured materials. The increase is specially noticeable in samples treated at $680{ }^{\circ} \mathrm{C}$ for $168 \mathrm{~h}$ (about $76 \%$ higher than the annealed samples) while it is lower in those treated at $900{ }^{\circ} \mathrm{C}$ for $2 \min$ (about $34 \%$ ). One explanation for this evolution is that the thermal treatments produce the Bi-2212 phase decomposition, producing small isolating precipitates inside the grains. These particles are growing with time until they reach the adequate size to act as effective pinning centers, increasing the $\mathrm{J}_{\mathrm{c}}$ values. Further thermal treatments increase the size of these precipitates, reducing their effectiveness as pinning centers and, as a consequence, decreasing the measured $\mathrm{J}_{\mathrm{c}}$ values.

\section{CONCLUSIONS}

$\mathrm{Bi}_{2} \mathrm{Sr}_{2.1} \mathrm{Ca}_{0.9} \mathrm{Cu}_{2} \mathrm{O}_{8+\delta}$ ceramics were successfully grown from the melt, through a LFZ process. After annealing process, nearly pure superconducting Bi-2212 phase has been obtained with reasonable electrical properties. Postannealing processes performed on annealed samples have demonstrated their usefulness in increasing electrical properties of $\mathrm{Bi}-2212$ textured samples. This increase is explained by the Bi-2212 phase thermal decomposition which can lead to the formation of small and well distributed isolating phases acting as effective pinning centers. This process is quick at high temperatures $\left(900{ }^{\circ} \mathrm{C}\right.$ ) and the maximum increase (around $35 \%$ ) is reached after only 2 minutes. On the other hand, the samples evolution with time is clearly seen at low temperature postannealing, reaching improvements of around $80 \%$ after $168 \mathrm{~h}$ thermal treatment. 
All these results indicate that it is possible to produce effective pinning centers with the adequate sizes by carefully controlling the $\mathrm{Bi}-2212$ phase decomposition process.

\section{Acknowledgements}

The authors acknowledge financial support from the Spanish MICINN-FEDER (Project MAT2008-00429), MINECO-FEDER (Project MAT2011-22719), the Universidad de Zaragoza (UZ2011-TEC-03) and the Gobierno de Aragón (Consolidated Research Groups T12 and T87). The technical contributions of C. Estepa and C. Gallego are also acknowledged. 


\section{References}

[1] Chen, M., Donzel, L., Lakner, M., Paul, W.: High temperature superconductors for power applications. J. Eur. Ceram. Soc. 24, 1815-1822 (2004).

[2] De la Fuente, G. F., Sotelo, A., Huang, Y., Ruiz, M. T., Badia, A., Angurel, L. A., Lera, F., Navarro, R., Rillo, C., Ibañez, R., Beltran, D., Sapiña, F., Beltran, A.: Polymer solution processing of (Bi,Pb)-Sr-Ca-Cu-O. Physica C 185-189, 509-510 (1991).

[3] Sotelo, A., Majewski, P., Park, H. S., Aldinger, F.: Synthesis of highly pure Bi-2223 ceramics using defined precursors. Physica C 272, 115-124 (1996).

[4] Rouessac, V., Wang, J., Provost, J., Desgardin, G.: Rapid synthesis of the Bi(Pb)$2223110 \mathrm{~K}$ superconductor by the EDTA sol-gel method. J. Mater. Sci. 31, 3387-3390 (1996).

[5] Sotelo, A., Szillat, H., Majewski, P., Aldinger, F.: Rapid synthesis of the Bi-2212 phase by a polymer matrix method. Supercond. Sci. Technol. 10, 717-720 (1997). [6] Sotelo, A., Mora, M., Madre, M. A., Amaveda, H., Diez, J. C., Angurel, L. A., Mayoral, M. C.: Study of the variation of the E-I curves in the superconducting to normal transition of Bi-2212 textured ceramics by $\mathrm{Pb}$ addition. Bol. Soc. Esp. Ceram. V. 45, 228-232 (2006).

[7] Shi, L., Dong, Q., Zhang, Y.: Effect of Pb-doping and annealing on the structure and $\mathrm{T}_{\mathrm{c}}$ of Bi-2212 superconductor. Physica C 341-348, 649-650 (2000).

[8] Dou, S. X., Song, K. H., Liu, H. K., Sorrell, C. C.: The interaction of Ag with Bi-PbSr-Ca-Cu-O superconductor. Physica C 160, 533-540 (1989).

[9] Madre, M. A., Amaveda, H., Mora, M., Sotelo, A., Angurel, L. A., Diez, J. C.: Ag doped $\left(\mathrm{Bi}_{1.6} \mathrm{~Pb}_{0.4}\right) \mathrm{Sr}_{2} \mathrm{CaCu}_{2} \mathrm{O}_{8+\delta}$ textured rods. Bol. Soc. Esp. Ceram. V. 47, 148-152 (2008). 
[10] Shi, D.: High Temperature Superconducting Materials Science and Engineering. Pergamon Press, Oxford (1995).

[11] Garnier, V., Caillard, R., Sotelo, A., Desgardin, G.: Relationship among synthesis, microstructure and properties in sinter-forged Bi-2212 ceramics. Physica C 319, 197 208 (1999).

[12] Huang, Y., de la Fuente, G. F., Sotelo, A., Badia, A., Lera, F., Navarro, R., Rillo, C., Ibañez, R., Beltran, D., Sapiña, F., Beltran, A.: (Bi,Pb) ${ }_{2} \mathrm{Sr}_{2} \mathrm{Ca}_{2} \mathrm{Cu}_{3} \mathrm{O}_{10+\delta}$ superconductor composites: ceramics vs. fibers. Physica C 185-189, 2401-2402 (1991). [13] Carrasco, M. F., Costa, F. M., Silva, R. F., Gimeno, F., Sotelo, A., Mora, M., Diez, J. C., Angurel, L. A.: Textured Bi-Sr-Ca-Cu-O rods processed by laser floating zone from solid state or melted precursors. Physica C 415, 163-171 (2004).

[14] Mora, M., Sotelo, A., Amaveda, H., Madre, M. A., Diez, J. C., Capel, F., LopezCepero, J. M.: Properties variation of Bi-2212 directionally solidified induced by $0.4 \mathrm{~Pb}$ substitution. J. Eur. Ceram. Soc. 27, 3959-3962 (2007).

[15] Sotelo, A., Rasekh, Sh., Madre, M. A., Diez, J. C.: Precursor influence on the elctrical properties of textured Bi-2212 superconductors. J. Supercond. Nov. Magn. 24, 19-25 (2011).

[16] Sotelo, A., Mora, M., Madre, M. A., Diez, J. C., Angurel, L. A., de la Fuente, G. F.: Ag distribution in thick Bi-2212 floating zone textured rods. J. Eur. Ceram. Soc. 25, 2947-2950 (2005).

[17] Zhao, B., Song, W. H., Wu, X. C., Du, J. J., Sun, Y. P., Wen, H. H., Zhao, Z. X.: Influence of $\mathrm{MgO}$ particle doping on flux pinning in $\mathrm{Bi}_{2} \mathrm{Sr}_{2} \mathrm{CaCu}_{2} \mathrm{O}_{\mathrm{y}}$ crystals. Physica $\mathrm{C}$ 361, 283-291 (2001). 
[18] Makarova, M. V., Kazin, P. E., Tretyakov, Yu. D., Jansen, M., Reissner, M.,

Steiner, W.: Zr, Hf, Mo and W-containing oxide phases as pinning aditives in Bi-2212 superconductor. Physica C 419, 61-69 (2005).

[19] Vinu, S., Sarun, P. M., Biju, A., Shabna, R., Guruswamy, P., Syamaprasad, U.: The effect of substitution of Eu on the critical current density and flux pinning properties of (Bi,Pb)-2212 superconductor. Supercond. Sci. Technol. 21, 04501 (2008).

[20] Weigand, M., Eisterer, M., Giannini, E., Weber, H. W.: Mixed state properties of $\mathrm{Bi}_{2} \mathrm{Sr}_{2} \mathrm{Ca}_{2} \mathrm{Cu}_{3} \mathrm{O}_{10+\delta}$ single crystals before and after neutron irradiation. Phys. Rev. B 81, $014516(2010)$.

[21] Majewski, P., Elschner, S., Aldinger, F.: Enhanced pinning by 2nd-phase precipitates in $\mathrm{Sr}$ rich $\mathrm{Bi}_{2} \mathrm{Sr}_{2} \mathrm{CaCu}_{2} \mathrm{O}_{8}$ ceramics. Physica C 249, 234-240 (1995).

[22] Majewski, P.: Phase diagram studies in the system Bi-Pb-Sr-Ca-Cu-O-Ag. Supercond. Sci. Technol. 10, 453-467 (1997).

[23] De la Fuente, G. F., Diez, J. C., Angurel, L. A., Peña, J. I., Sotelo, A., Navarro, R.: Wavelength dependance in laser floating zone processing. A case study with Bi-Sr-CaCu-O superconductors. Adv. Mater. 7, 853-856 (1995).

[24] Funahashi, R., Matsubara, I., Ueno, K., Ishikawa, H.: Mechanism of $\mathrm{Bi}_{2} \mathrm{Sr}_{2} \mathrm{CaCu}_{2} \mathrm{O}_{\mathrm{x}}$ crystallization and superconducting properties for $\mathrm{Bi}_{2} \mathrm{Sr}_{2} \mathrm{CaCu}_{2} \mathrm{O}_{\mathrm{x}} / \mathrm{Ag}$ tapes prepared using isothermal partial melting method. Physica C 311, 107-121 (1999). [25] Mora, M., Martinez, E., Diez, J. C., Angurel, L. A., de la Fuente, G. F.: Phase growth and microstructure modifications induced by annealing in highly textured superconducting Bi-2212 thin rods. J. Mater. Res. 15, 614-620 (2000). [26] Vanderah, T. A.: Chemistry of superconductor materials. Noyes publications, New Jersey (1992). 
Table I. $\mathrm{T}_{\mathrm{c}}$ values obtained for the annealed and postannealed samples, as a function of temperature and time, obtained from the $\rho$-T data.

\begin{tabular}{|c|c|c|}
\hline Thermal treatment & Time & $\mathbf{T}_{\mathrm{c}}(\mathrm{K})$ \\
\hline Annealed & ------ & 90.0 \\
\hline \multirow{13}{*}{$680^{\circ} \mathrm{C}$} & $24 \mathrm{~h}$ & 88.0 \\
\hline & $48 \mathrm{~h}$ & 87.8 \\
\hline & $72 \mathrm{~h}$ & 88.3 \\
\hline & $96 \mathrm{~h}$ & 88.4 \\
\hline & $120 \mathrm{~h}$ & 89.5 \\
\hline & $144 \mathrm{~h}$ & 89.3 \\
\hline & $168 \mathrm{~h}$ & 89.7 \\
\hline & $192 \mathrm{~h}$ & 89.7 \\
\hline & $216 \mathrm{~h}$ & 88.3 \\
\hline & $240 \mathrm{~h}$ & 87.5 \\
\hline & $264 \mathrm{~h}$ & 86.6 \\
\hline & $288 \mathrm{~h}$ & 87.7 \\
\hline & $312 \mathrm{~h}$ & 87.1 \\
\hline \multirow{4}{*}{$900^{\circ} \mathrm{C}$} & $1 \mathrm{~min}$ & 89.0 \\
\hline & $2 \min$ & 88.0 \\
\hline & $3 \mathrm{~min}$ & 90.0 \\
\hline & $4 \mathrm{~min}$ & 90.6 \\
\hline
\end{tabular}


Table II. $\mathrm{I}_{\mathrm{c}}$, diameter and $\mathrm{J}_{\mathrm{c}}$ values obtained for the annealed and postannealed samples at different temperatures and times.

\begin{tabular}{|c|c|c|c|}
\hline Thermal treatment & Time & $\mathbf{I}_{\mathrm{c}}(\mathrm{A})$ & $J_{c}\left(A / \mathbf{c m}^{2}\right)$ \\
\hline Annealed & ------ & 63.6 & 2065 \\
\hline \multirow{13}{*}{$680^{\circ} \mathrm{C}$} & $24 \mathrm{~h}$ & 97.1 & 3183 \\
\hline & $48 \mathrm{~h}$ & 106.0 & 3312 \\
\hline & $72 \mathrm{~h}$ & 96.3 & 3332 \\
\hline & $96 \mathrm{~h}$ & 90.4 & 3373 \\
\hline & $120 \mathrm{~h}$ & 105.6 & 3428 \\
\hline & $144 \mathrm{~h}$ & 101.6 & 3514 \\
\hline & $168 \mathrm{~h}$ & 100 & 3636 \\
\hline & $192 \mathrm{~h}$ & 97.1 & 3468 \\
\hline & $216 \mathrm{~h}$ & 108.9 & 3403 \\
\hline & $240 \mathrm{~h}$ & 106.9 & 3404 \\
\hline & $264 \mathrm{~h}$ & 97.8 & 3056 \\
\hline & $288 \mathrm{~h}$ & 91.5 & 3000 \\
\hline & $312 \mathrm{~h}$ & 81.9 & 2712 \\
\hline \multirow{4}{*}{$900{ }^{\circ} \mathrm{C}$} & $1 \mathrm{~min}$ & 59.6 & 2374 \\
\hline & $2 \mathrm{~min}$ & 69.3 & 2761 \\
\hline & $3 \mathrm{~min}$ & 66.0 & 2462 \\
\hline & $4 \mathrm{~min}$ & 63.5 & 2131 \\
\hline
\end{tabular}




\section{Figure captions}

Figure 1. Powder XRD patterns of the Bi-2212 textured ceramics: before (a) and after postannealing (b) at $680{ }^{\circ} \mathrm{C}$ for $168 \mathrm{~h}$; (c) at $680^{\circ} \mathrm{C}$ for $312 \mathrm{~h}$; (d) at $900{ }^{\circ} \mathrm{C}$ for $1 \mathrm{~min}$; and (e) at $900{ }^{\circ} \mathrm{C}$ for 4 min. $\mathrm{Bi}-2212$ diffraction peaks are identified by the corresponding crystallographic planes.

Figure 2. SEM micrographs of polished longitudinal sections of Bi-2212 textured materials before (a) and after postannealing (b) at $680{ }^{\circ} \mathrm{C}$ for $168 \mathrm{~h}$; (c) at $680{ }^{\circ} \mathrm{C}$ for $312 \mathrm{~h}$; (d) at $900{ }^{\circ} \mathrm{C}$ for $2 \mathrm{~min}$; and (e) at $900{ }^{\circ} \mathrm{C}$ for $4 \mathrm{~min}$. The numbers indicate the different phases: 1) $\mathrm{Bi}-2212$; 2) $\mathrm{Bi}-2201 ; 3)(\mathrm{Sr}, \mathrm{Ca}) \mathrm{CuO}_{2}$; 4) $\left.\mathrm{Bi}_{2+x}(\mathrm{Sr}, \mathrm{Ca})_{2} \mathrm{CuO}_{6+\delta} ; 5\right)$ $\left.\mathrm{Sr}_{3} \mathrm{Bi}_{2} \mathrm{O}_{6} ; 6\right) \mathrm{Sr}_{14} \mathrm{Cu}_{24} \mathrm{O}_{41-x}$; and 7) $(\mathrm{Sr}, \mathrm{Ca}) \mathrm{Cu}_{2} \mathrm{O}_{3}$.

Figure 3. Temperature dependence of electrical resistivity of textured Bi-2212 samples before (•) and after postannealing at $680{ }^{\circ} \mathrm{C}$ for $168(\square)$ and $312 \mathrm{~h}(\boldsymbol{\nabla})$ and $900{ }^{\circ} \mathrm{C}$ for 2 $(\Delta)$ and $4 \min (\diamond)$.

Figure 4. $\mathrm{J}_{\mathrm{c}}$ relative increase, compared with the annealed samples, as a function of the postannealing time at a) 680 ; and b) $900{ }^{\circ} \mathrm{C}$. 
Figure 1

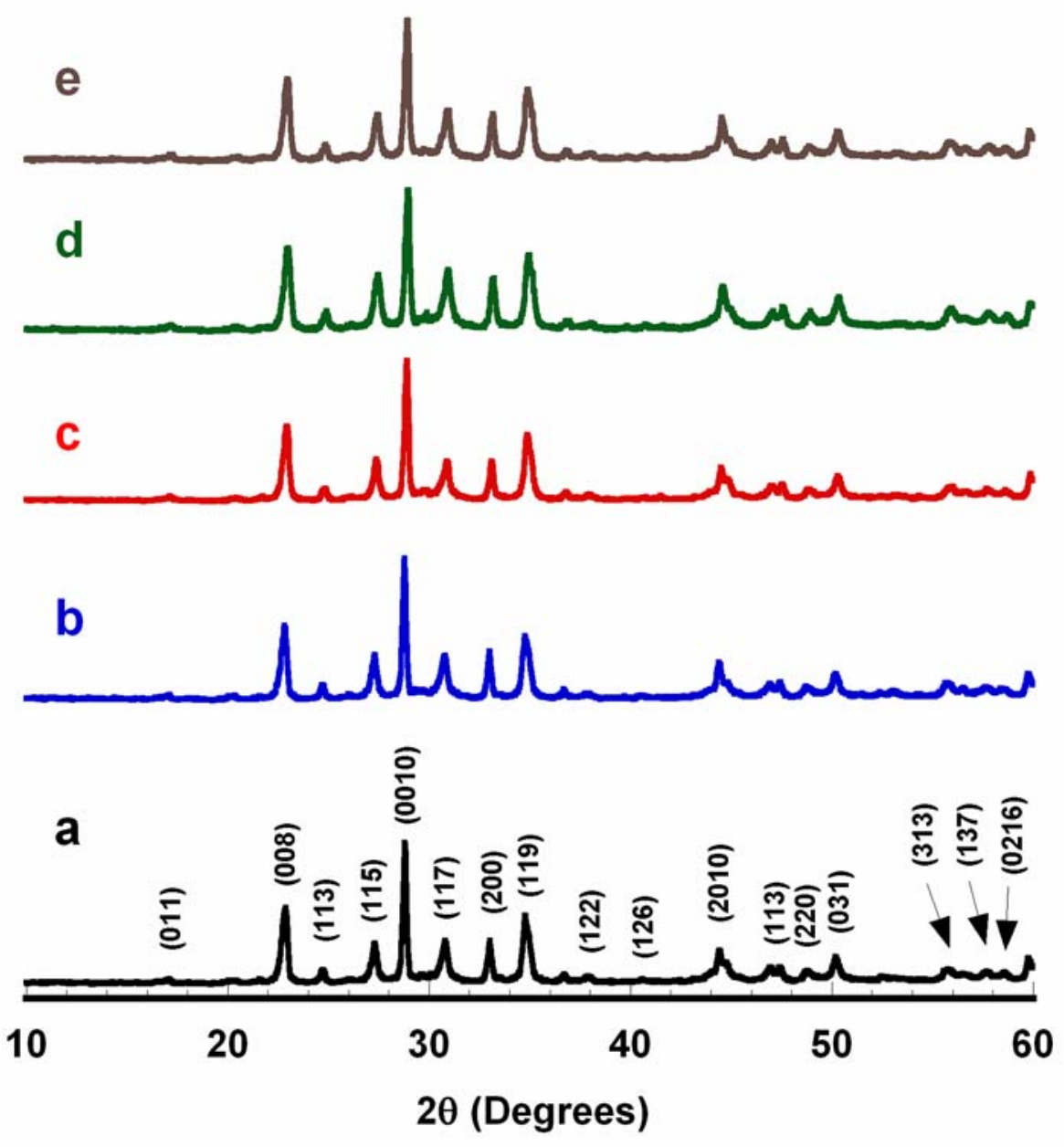


Figure 2

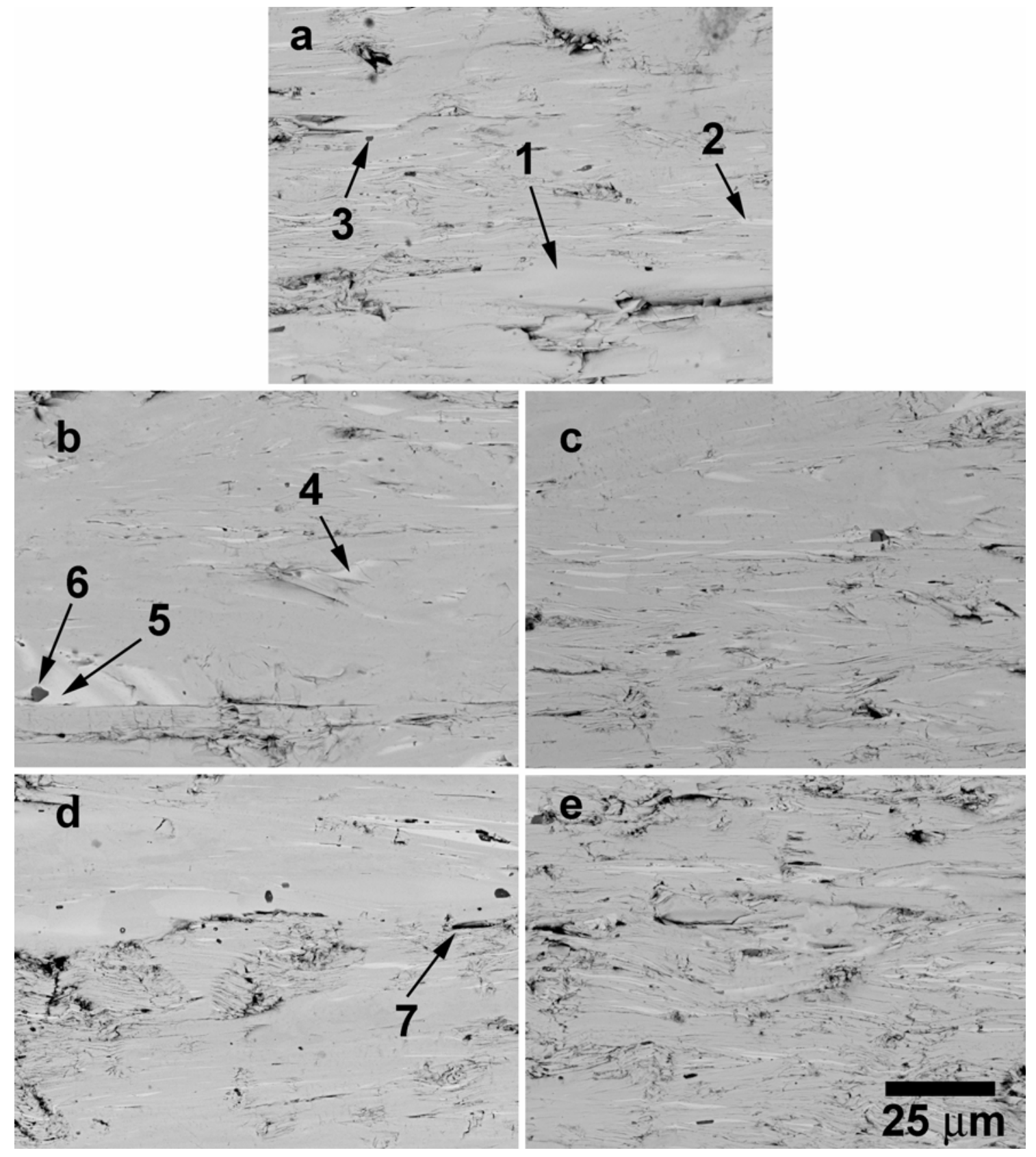


Figure 3

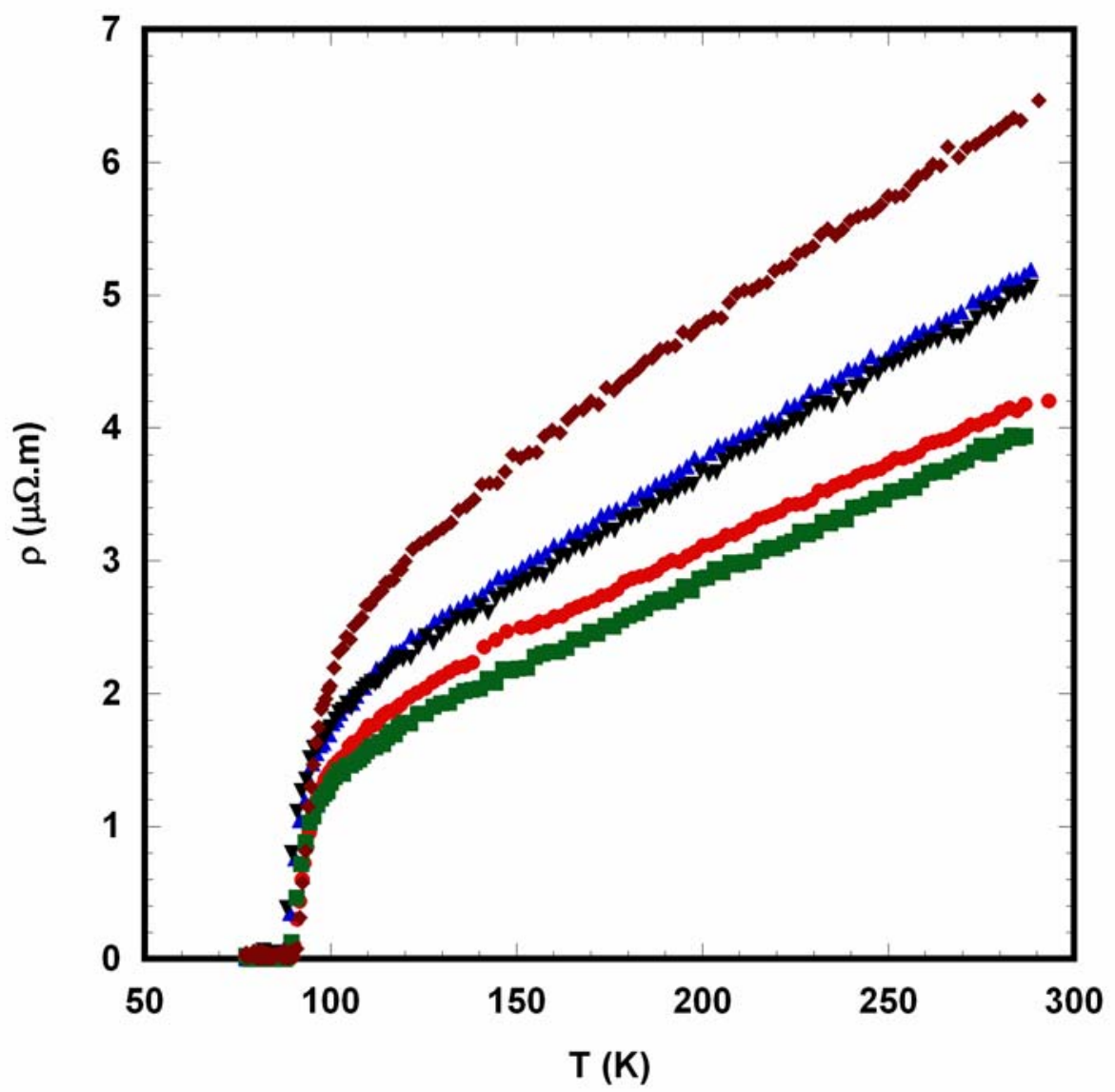


Figure 4
